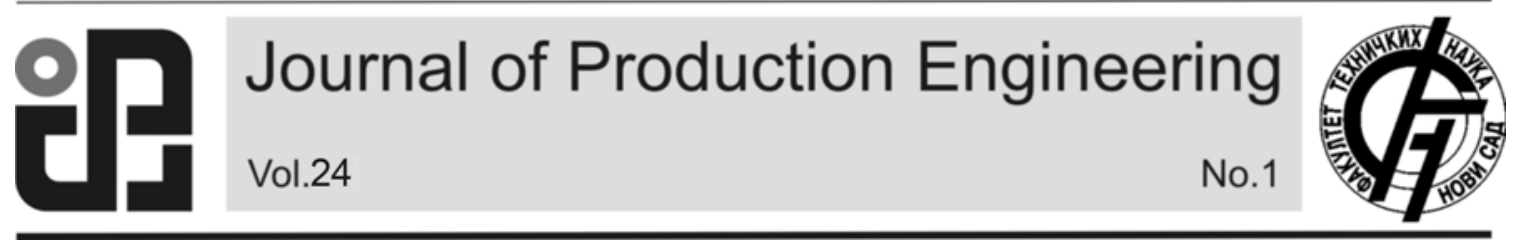

JPE (2021) Vol.24 (1)

Original Scientific Paper

Štrbac, B., Ranisavljev, M., Runje, B., Horvatić Novak, A., Razumić, A., Hadžistević, M.

\title{
TOTAL UNCERTAINTY IN THE PRODUCT LIFE CYCLE - AN EXAMPLE ON COORDINATE MEASUREMENT SYSTEMS
}

Received: 11 January 2021 / Accepted: 19 March 2021

\begin{abstract}
The measurement result if expressed without confidence interval estimate it is not complete. Confidence Interval is characterized as uncertainty and is a quantitative indicator of the measurement result quality. Measurement uncertainty is mainly caused by factors such as measuring instrument, operator, workpiece, applied strategy and/or measurement conditions. GPS, a standard defining geometrical specification and product verification, integrates the entire product geometry description and defines uncertainty at each stage. The result is a total uncertainty which is usually significantly greater than measurement uncertainty (sometimes twice greater). This study provides a method for estimating total measurement uncertainty of determining flatness error using coordinate measuring machines (CMM).
\end{abstract}

Key words: geometrical product specification (GPS), uncertainty, flatness, coordinate measurement machine $(C M M)$

Ukupna nesigurnost u životnom ciklusu proizvoda - primer na koordinatnim mernim sistemima. Rezultat merenja izražen bez intervala poverenja nije kompletan. Interval poverenja je okarakterisan kao nesigurnost $i$ kvantitativni je indikator kvaliteta mernog rezultata. Glavni uzročnici merne nesigurnosti su faktori kao što su merna oprema, metrolog, radni predmet, strategija merenja i/ili opšti uslovi merenja. GPS, standard koji definiše geometrijsku specifikaciju proizvoda i verifikaciju proizvoda, integriše celokupan geometrijski opis proizvoda $i$ definiše nesigurnost u svakoj fazi. Rezultat toga predstavlja ukupna nesigurnost koja je, obično, značajno veća nego merna nesigurnost (ponekad i dva puta veća). Ova studija daje metod za procenu ukupne merne nesigurnosti pri određivanju greške ravnosti koristeći koordinatnu mernu mašinu (KMM).

Ključne reči: Geometrijska specifikacija proizvoda (GPS), nesigurnost, ravnost, koordinatna merna mašina (KMM)

\section{INTRODUCTION}

The modern industrial world sometimes imposes very narrow tolerances at assemblies and sub assemblies in order to enable application of functional requirements. Workpieces paired for the purpose of sealing or sliding or those that have to be appropriately oriented, often have to be subjected to estimating flatness errors. Flatness error verified by a measuring equipment with estimated measuring uncertainty, has to be within a field of specification if a compliance with ISO 14253-1 [1] is required. Lately, coordinate measuring machines are the most commonly used measuring instrument for assessing flatness errors because of their flexibility. However, due to many factors and their interactions, evaluation of uncertainty of CMM measurement is a complex task. This is one of the trendiest research topics in the field of production metrology in the last two decades. Research efforts of leading metrology institutes and a number of EU projects resulted in creating and implementation of standardized methods for estimating measuring uncertainty for CMM with the support of ISO [2, 3]. The new generation of geometrical product specifications went a step further in relation to the term "uncertainty". The GPS concept connects the entire course of the geometry of the product, from functionality, specification, production, to verification and represents the workpiece in three different "worlds"
- operators [4]. The first operator is nominal - ideal model. The second specification operator or "Skin" model is the nominal model in combination with the allowed tolerances, while the third operator is represented by verification procedures on real workpiece. Presentation of the geometry of the workpiece in this way corresponds to the steps of the $\mathrm{CAD} / \mathrm{CAM} / \mathrm{CAQ}$ systems. Checking the workpiece quality conformity is performed by comparing the specification and verification operators. An approach based on operators and operations significantly improves the management of data related to the workpiece, so that the minimization of uncertainty is in relation to probable interpretations of geometric specifications. As a guarantee of the best description of the workpiece and estimate of its correspondence with the functional requirements, GPS language introduces defining new factors of uncertainty that are able to characterize products in various stages of its life cycle. In the improved GPS system, besides the measurement uncertainty, the uncertainty of correlation, uncertainty of specification, uncertainty of conformity and total uncertainty are defined.

Therefore, the decision of conformity / nonconformity of a product should be based on the total uncertainty and not, as it has usually been the practice, on the measurement uncertainty. This issue certainly did not attract sufficient attention and research efforts. Wen et al. carried out the estimation of uncertainty for 
measuring flatness on CMM in accordance with GPS, but they did not define uncertainty of specifications and conformity [5]. Ruffa et al. estimated the total uncertainty [6] for estimating roundness error. This research describes how to minimize the uncertainty of specifications, correlation and conformity. For the evaluation of uncertainty, analytical GUM method and computer bootstrap were used. Ricci et al. have made the most comprehensive approach on estimating the total uncertainty for measuring flatness error using CMM [7].

The research aims are to present a methodology for the estimating the total uncertainty in accordance with the standard instruction for estimating total uncertainty (GUM) [8] on a concrete example of measuring flatness error using CMM.

\section{SPECIFICATION AND VERIFICATION OF FLATNESS}

According to ISO 12781-1, flatness error is defined as the area between the two parallel planes All points sampled from the measured surface must be placed within the space limited by two planes, i.e. tolerance space [9].

According to GPS, a complete specification operator for flatness executes all operations necessary for testing the conformity of an actual plane as imagined by the designer. A specification operator consists of the following operations: partition, extraction, filtration, association and evaluation. Partition is used in order to identify the boundaries of geometric primitives (point, line, circle, plane, cylinder) obtained from actual surfaces. The operation of extraction includes describing realistic geometry via the position of sampling points obtained by a measuring instrument. The operation of extraction is performed according to a previously determined measuring strategy. Filtration of the measured values includes separating deviations of various origin (form deviation, waviness, roughness). It is also used for the elimination of accidental measurement deviations. The operaton of association uses fit algorithms for mathematical representation of a surface based on sampling points. Evaluation is used for determining errors, in this case flatness error.

A complete specification operator implies the existence of a tolerance frame in technical documentation, as shown in Fig.1.

\section{$\square 0.0004 \lambda_{\mathrm{C}}=2.5$ LS}

Fig. 1. A completely defined specification operator for flatness tolerance

A metrologist needs to, unambiguously and in accordance with the principle of duality, apply the operations from the specification operator in the verification operator. In the picture, the parameter ,$\lambda c=2.5$ "defines the operations of extraction and filtration. According to ISO 12781-2 [10], an appropriate filter with cut-off wavelength $\lambda c$ has to be chosen with the aim of extraction of the componen error of a form required by the geometric specification.
Likewise, the accepted filter value defines, for the chosen diameter of the top of the measuring probe, the minimum number of points that needs to be sampled in the " grid" measuring strategy. It is worth mentioning that in the cases when sampling is performed in the discrete mode, the operation of filtration will only be efficient in the ideal verification operator. However, in most case, this can hardly be applied in practice due to the problems of time and price. Therefore, simplified verification operators with a reduced number of measuring points are introduced. In such operators, filtration will not affect measurement results and it will cause uncertainty. The parameter designated as LS (least square) in the picture denotes the fit method or the algorithm used for obtaining, in this case, the plane of reference. Besides the LS method, the minimum zone (MZ) method can also be used. There is no unanimous opinion among scientists and professionals on the choice of the associative criterion. LS has been used more frequently, whereas in MZ the flatness error is usually smaller and the method has been recommended by ISO 1101 [11].

Finally, form deviation can be explained as the difference between the maximum and minimum local flatness deviation..

Flatness error is defined as [12]:

$$
\delta=\max _{1 \leq i \leq n}\left\{d_{i}\right\}-\min _{1 \leq i \leq n}\left\{d_{i}\right\}
$$

where $d_{i}$ represents the maximum and minimum distance of extreme points in relation to the plane of reference and is presented as an equation:

$$
d_{i}=\frac{z_{i}-a x_{i}-b y_{i}-c}{\sqrt{1+a^{2}+b^{2}}}
$$

with flatness error:

$$
\delta=\frac{\left(z_{\max }-z_{\min }\right)-a\left(x_{\max }-x_{\min }\right)-b\left(y_{\max }-y_{\min }\right)}{\sqrt{1+a^{2}+b^{2}}} \text { (3). }
$$

The two points that are farthest apart in relation to the plane of reference are presented in coordinates $\left(x_{\max }\right.$, $\left.y_{\max }, z_{\max }\right)$ and $\left(x_{\min }, y_{\min }, z_{\min }\right)$.

This way, an ideal specification operator is defined, and according to the principle of duality, an ideal verification operator can be derived from it. Only in such a scenario can the total uncertainty be equated to measurement uncertainty. In all other cases, other factors of total uncertainty should be considered.

\section{TOTAL UNCERTAINTY AND METHODOLOGY OF ITS ESTIMATION}

The factors of total uncertainty are presented in ISO 17450-2 as shown in Fig.2 [13,14]. Correlation uncertainty is a measure of the ability of geometric specifications to guarantee the functional requirements of what it is intended for. The role of specification uncertainty is to quantify ambiguity in specification operators and this is the case when the specification operator is not complete or when a metrologist introduces a simplified verification operator. Measurment uncertainty gathers all uncertainties generated in the use of a real verification operator. This 
corresponds to the classic concept of measurement uncertainty and consists of the sum (according to GUM) of the uncertainty of the applied method and implementation uncertainty. Measurement uncertainty takes into account the imperfections of measuring instruments and deliberate deviations from the ideal verification operator.

In our example, there is full compliance with the ideal verification operator and total uncertainty can only be ascribed to implementation uncertainty. Uncertainties generated as a result of temperature or temperature gradient have been neglected because the experiment is carried out in an air-conditioned laboratory. In that case, uncertainty will be affected by CMM point sampling by means of hardware and probe system, and uncertainty in the operation of association when the referential plane is being determined. Uncertainty can be calculated in the following equation:

$$
\begin{gathered}
u_{\delta}^{2}=\frac{\partial \delta}{\partial x_{1}} u_{x_{1}}^{2}+\frac{\partial \delta}{\partial x_{2}} u_{x_{2}}^{2}+\frac{\partial \delta}{\delta y_{1}} u_{y_{1}}^{2}+\frac{\partial \delta}{\partial y_{2}} u_{y_{2}} \\
+ \\
+\frac{\partial \delta}{\partial z_{1}} u_{z_{1}}^{2}+\frac{\partial \delta}{\partial z_{2}} u_{z_{2}}^{2}+\frac{\partial \delta}{\delta a} u_{a}^{2}+\frac{\partial \delta}{\partial b} u_{b}^{2}+ \\
+2 \frac{2 \delta}{\partial a} \frac{\partial \delta}{\partial b} \rho_{a b} u_{a} u_{b}
\end{gathered}
$$

The first two rows in formula (4) refer to uncertainty in extreme points of sampling generated by hardware components of a CMM and probe system, whereas the third row refers to the uncertainty of the applied associative method.

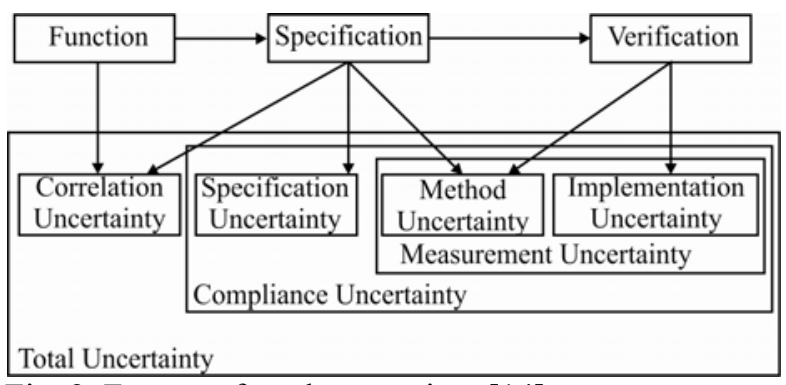

Fig. 2. Factors of total uncertainty [14]

\section{CASE STUDY}

The verification of the proposed method has been performed on a CMM Carl Zeiss CONTURA g2 RDS $\left(\mathrm{MPE}_{\mathrm{E}}=1.9+\mathrm{L} / 330\right)$ while measuring the flatness of a optical flat $d=60 \mathrm{~mm}$ (Fig.3). This workpiece can be said to represent the artifact of flatness. Is the specified flatness error is $\delta=0.0004 \mathrm{~mm}$. This error is under the domain of accuracy CMM and in this way was eliminated contribution uncertainty - form error. This is important because some studies have shown that this factor in the interactions to the uncertainty of sample points can be one of the most influential on measurement uncertainty [15]. According to the specification operator, for the defined value $\lambda c$, the measured object needs to be measured in 21876 points at the distance of $\mathrm{d}=0.357 \mathrm{~mm}$, with a probe tip $\mathrm{r}=0.55 \mathrm{~mm}$. For the filtration of points, i.e. for eliminating the frequencies of shorter wavelengths such as roughness and waviness, a Gaussian filter is used according to ISO $16610-21 / 28$ [16]. The transfer at limit wavelength is $50 \%$. After sampling, the parameters of the referential plane were obtained and the flatness error was determined. The error was much greater than the measure on the optical flat (Fig.4). The expanded uncertainty, which in this case refers only to implementation uncertainty, using formula (4) and coverage factor $\mathrm{k}=2$, amounts to $\mathrm{U}=0.6 \mu \mathrm{m}$. It needs to be mentioned that simplification was introduced here and that the uncertainty of the extreme sampled points was taken as $\mathrm{MPE}_{\mathrm{E}} / 6$. The obtained result of uncertainty should be verified in a more precise calibration procedure such as interferometry. Also, more effort is required for the investigation of hardware errors, which is probably different from the applied simplification.

\section{CONCLUSION}

Being acquainted with the value of total uncertainty is the most important concept according to a new generation of geometrical product specifications and is the basis for making decisions about accepting or rejecting workpieces. Total uncertainty is not very common in industry so it should be promoted as much as possible.

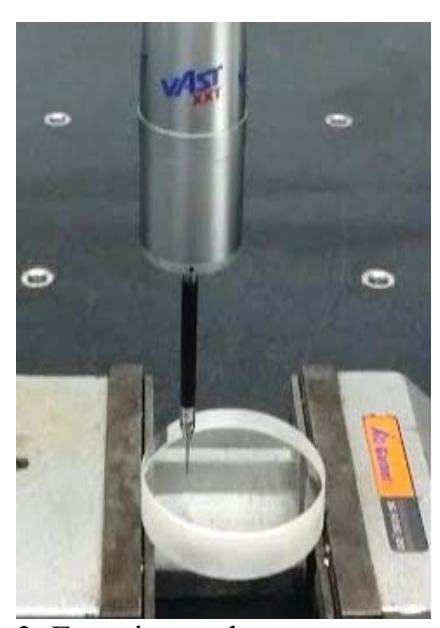

Fig. 3. Experimental setup

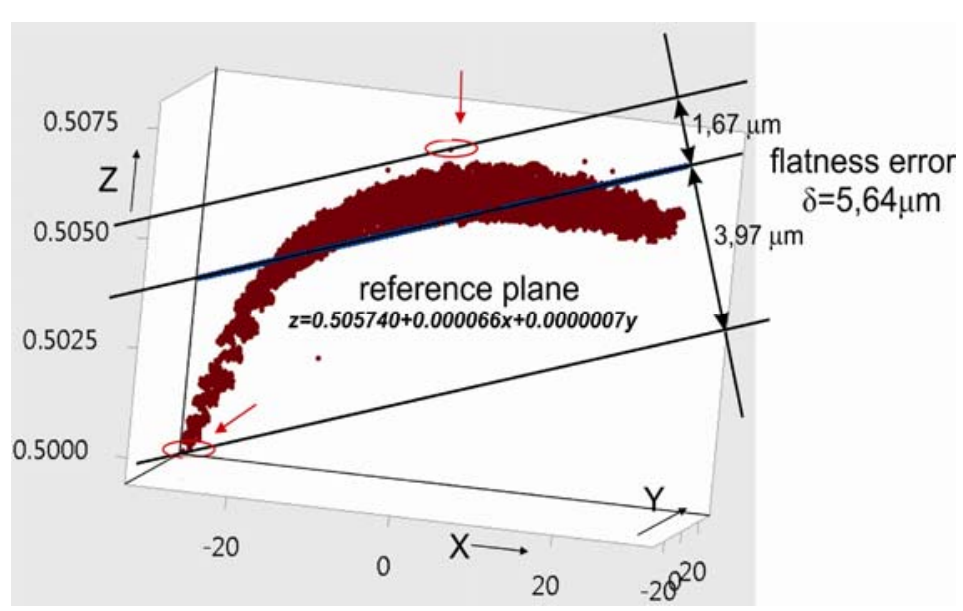

Fig. 4. Sampling points, reference plane (LS) and flatness error 


\section{REFERENCES}

[1] ISO 14253-1:1998. Geometrical Product Specifications (GPS) - Inspection by measurement of workpieces and measuring equipment - Part 1: Decision rules for proving conformance or non conformance with specifications, ISO, 1998.

[2] ISO/TS 15530-3:2004. Geometrical Product Specifications (GPS) - Coordinate measuring machines (CMM): Technique for determining the uncertainty of measurement - Part 3: Use of calibrated workpieces or standards, 2004.

[3] ISO, 2004. ISO/TS 15530-4:2008. Geometrical Product Specifications (GPS) - Coordinate measuring machines (CMM): Technique for determining the uncertainty of measurement - Part 4: Evaluating task-specific measurement uncertainty using simulation. ISO, 2008.

[4] Humienny, Z.: State of art in standardization in GPS area" CIRP Journal of Manufacturing Science and Technology, Vol 2, No 1, p.p. 1-7, 2009.

[5] Wen, X-L., Zhu, X-C., Zhao, B-Y., Wang, D-X, Wang, F-L.: Flatness error evoluation and verification based on new generation geometrical product specification (GPS), Precision Engineering, Vol. 36, pp. 70-76, 2012.

[6] Ruffa, S., Panciani, G.D., Ricci, F., Vicario, G.: Assessing Measurement Uncertainty in CMM measurements: Comparison of Different Approaches, International Journal of Metrology and Quality Engineering, Vol. 4, pp. 163-168, 2013.

[7] Ricci, F., Scott, J.P., Jiang, X.: A categorical model for uncertainty and cost management within the Geometrical Product Specification (GPS) Framework, Precision Engineering, Vol. 37, pp. 265-274, 2013.

[8] ISO/IEC Guide 98-3:2008. Uncertainty of measurement - Part 3: Guide to the expression of uncertainty in measurement (GUM:1995). ISO/IEC, 2008.

[9] ISO 12781-1, Geometrical product specifications (GPS) - Flatness - Part 1: Vocabulary and parameters of flatness, 2011.

[10] ISO 12781-2: Geometrical product specifications (GPS) - Flatness - Part 2: Specification operators, 2011.

[11] ISO 1101: Geometrical product specifications (GPS) - Geometrical tolerancing - Tolerances of form, orientation, location and run-out, 2012.

[12] Cui, C., Fu, S., Huang, F.: Research on the uncertainties from different form error evaluation methods by CMM sampling, International Journal of Advanced Manufacturing Technology, Vol. 43, pp. 136-145, 2009.

[13] ISO/TS 17450-2, Geometrical product specification (GPS) - General concept - Part 2: Basic tenets, specifications, operators and uncertainties. 2002.

[14] Wang, J.X., Jiang, X., Ma, L.M., Xu, Z.G., Li, Z.: Decision rules for workpieces based on total uncertainty, International Journal of Advanced Manufacturing Technology, Vol. 28, pp. 11691174, 2006.
[15] Kruth, J.P., Van Gestel, N., Bleys, P., Welkenhuyzen, F.: „Uncertainty determination for CMMs by Monte Carlo simulation integrating feature form deviations", CIRP - Manufacturing Technology, Vol. 58, pp. 463-466, 2009.

[16] ISO 16610-21, Geometrical product specifications (GPS) - Filtration - Part 21: Linear profile filters: Gaussian filters, 2011.

Authors: Assist. Professor Branko Štrbac PhD, Miloš Ranisavljev B.Sc, Professor Miodrag Hadžistević PhD, University of Novi Sad, Faculty of Technical Sciences, Trg Dositeja Obradovica 6, 21000 Novi Sad, Serbia, Phone.: +381 21 450-366,

E-mail: strbacb@uns.ac.rs; ranisavljev@uns.ac.rs; miodrags@uns.ac.rs

Professor Biserka Runje PhD, Assist. Amalija Horvatić Novak PhD, Assist. Andrej Razumić M.Sc, Faculty of Mechanical Engineering and Naval Architecture, University of Zagreb, Ivana Lucica 5, 10000 Zagreb, Croatia

E-mail: biserka.runje $@$,fsb.hr; amalija.horvatic@fsb.hr; Andrej.Razumic@fsb.hr; 